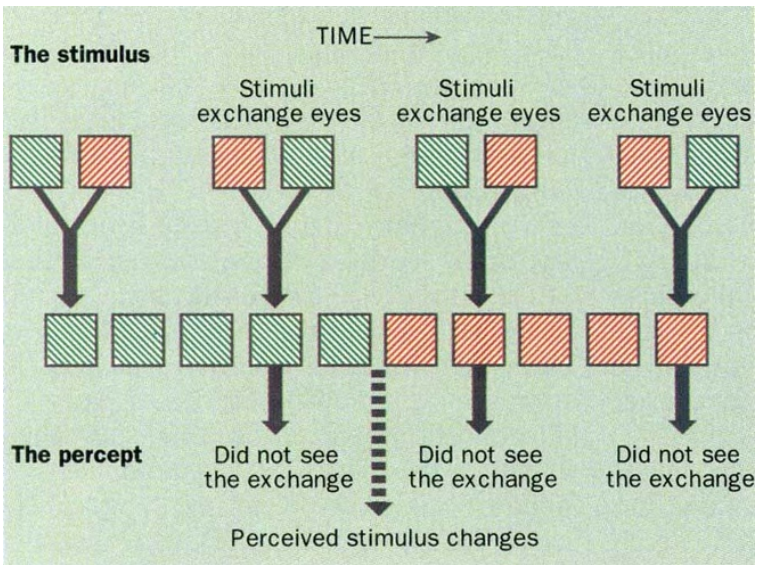

FIG. 2 Logothetis et al. present oblique bars to one eye and orthogonally oriented bars to the other. Three times a second, the stimuli exchange eyes. Under the conditions described in the text, observers do not see this exchange. Instead, the visual system tries to hold on to a stable percept, even if the input supporting that perception moves from the left to the right eye.

competition. What they did and saw is illustrated in Fig. 2. They used stimuli similar to those in Fig. 1. They flashed them on and off at $18 \mathrm{~Hz}$ to produce a continuous flicker. Their critical manipulation was to exchange the stimuli of the left and right eyes three times a second. Thus, looking with just one eye, you would see a flickering grating repeatedly changing orientation by $90^{\circ}$. Their surprising finding is that this exchange is not seen when both eyes are open.

This is a clear 'win' for the stimulusspecific mechanism. It is managing to preserve the perception of lines of one orientation, even when those lines shift from one eye to the other. If the interocular mechanism were more potent, you would see changes in the currently winning, dominant eye and so you would see the orientations change ${ }^{7}$.

It is not entirely clear why the conditions used by Logothetis et al. favour the putative stimulus-specific mechanism. There are ways to eliminate rivalry entirely and produce the plaid pattern of Fig. 1a. Changing from high-contrast bars of black and white to low-contrast bars of very slightly different shades of grey will do it $^{8}$. So will flickering the pattern on and off every fifth second or so 9 . The authors' stimuli are flickering gratings of 20 per cent contrast - not low or slow enough to eliminate rivalry, but perhaps an intermediate state that preferentially disrupts the interocular processes.

There is some evidence to support the idea that local interocular competition has been disrupted. Logothetis and colleagues report whole eye rivalry (Fig. 1b) with their $3 \times 3$ degree stimuli. Whole eye rivalry usually requires stimuli smaller than about $1 \mathrm{deg}$, so whole eye rivalry with such a large stimulus suggests reduced local interocular competition. In informal observations in my laboratory, this dominance of stimulus factors over interocular factors is reduced if either the contrast is raised or the flicker is eliminated. Further parametric work is needed on this point.

If this were merely an illustration of some arcane details of binocular rivalry, it would be of only limited interest. However, its real value lies in its potential to bring under scientific scrutiny the stimulus-specific mechanism described above. Normal visual perception always represents the effort to impose a single interpretation on ambiguous visual input. As a slightly strained example, consider the full stop at the end of this sentence. It could be a speck of dirt. It could be a small portal into a black void beyond the page. You see it as a full stop because your visual system renders the verdict that a full stop is the most plausible interpretation of that black spot in the image.

Every psychology text contains illustrations of what are called 'ambiguous' or 'reversible' figures - cleverly contrived cases that prevent the visual system from settling on a single interpretation. Examples include the Necker cube and Rubin's face-vase figure. In these cases, one stimulus produces two plausible perceptions. Binocular rivalry allows us to present two arbitrary competing stimuli to the visual system. The demonstration by Logothetis et al. enables us to minimize the usual interocular competition. This opens the way for experiments that pit one percept against another in order to uncover the rules that are used to resolve perceptual ambiguity.

Jeremy $M$. Wolfe is at Harvard Medical School and Brigham and Women's Hospital, Center for Ophthalmic Research, 221 Longwood Avenue, Boston, Massachusetts 02158, USA.

\footnotetext{
1. DuTour, E.-F. Discussion on a Question of Optics, Memoirs of Foreign Scientists Vol. 3, pages 514 and following (Academie des Sciences. Mémoires de Mathématique et de Physique Préséntes par Divers Savants 4, 499-511(1763)). (Unpublished translation available from R. P. O'Shea; e-mail: r oshea@otago.ac.nz.)

2. Logothetis, N. K., Leopold, D. A. \& Sheinberg, D. L. Nature 380, 621-624 (1996).

3. Leopold, D. A. \& Logothetis, N. K. Nature 379, 549-553 (1996).

4. Crick, F. Nature 379, 485-486 (1996)

5. Wolfe, J. M. Perception 12, 447-456 (1983).

6. Blake, R., O'Shea, R. P. \& Mueller, P. J. Visual Neurosci. 8, 469-478 (1992)

7. Blake, R., Westendorf, D. H. \& Overton, R. Perception 9 , 223-231 (1980)

8. Liu, L., Tyler, C. W. \& Schor, C. Vision Res. 32, 1471-1480 (1992)

9. Wolfe, J. M. Perception 12, 447-456 (1983)
}

\section{Inner ferment}

THE greenhouse effect is not a purely human invention. The world's cows and termites eat plants, and ferment their saccharides internally to carbon dioxide and the potent greenhouse gas methane. They emit about $\mathbf{3 0 0}$ million tonnes of it into the air each year. And, of course, the plants that evade the cows and termites still die sometime, and similar organisms degrade their saccharides, again to carbon dioxide and methane.

These fermentations proceed through a 'consortium' of many different microbes. The primary gaseous product is hydrogen. This is then seized by the methanogens and combined with carbon dioxide to give methane. For dairy farmers, methane is a pure waste product. They try to reduce it by feeding their cows with 'ionophores' - chelating agents that inhibit the methanogens by seizing the sodium and potassium ions they need for their hydrogen-uptake chemistry.

Curiously enough, we ourselves seem to have solved this problem. We all make hydrogen in our large intestine; even Escherichia coli can make hydrogen from saccharides, though some clostridia are better at it. But only a third of us take it on to methane. The rest of us somehow suppress our internal methanogens, and emit hydrogen from our rear ends.

Now some Streptomyces moulds put out natural ionophore chelating agents, which kill rival bacteria by stealing their potassium. The methane-free majority among us, says Daedalus, must harbour a bug that makes a similar inhibitor. So DREADCO biochemists are studying the internal flora of volunteers, to identify this organism and the inhibitor it uses. They plan to insert its crucial genes into promising members of the internal flora of cows and termites, and the free-living cellulose-rotting organisms. The new, improved organisms will displace and suppress the methanogens. Some of them may even put the hydrogen to better use - perhaps to make acetate.

When all is ready, DREADCO will release the new genetically engineered organisms into the environment. They will spread rapidly. Every cow and termite in the world will have a mighty internal spasm as the new internal regime takes hold. Thereafter, they won't produce methane, but hydrogen instead.

Environmentalists will agonize over the use of wicked genetic engineering to counter the wicked greenhouse effect. The rest of us will enjoy the benefits. Not only is hydrogen a non-greenhouse gas; it is widely acclaimed as the virtuous, nonpolluting fuel of the future. Generated in fermenters and used to power fuel cells, it will be the ultimate renewable source of energy.

David Jones 